\title{
The Vocabulary Knowledge of Saudi EFL Tertiary Students
}

\author{
Sultan Altalhab ${ }^{1}$ \\ ${ }^{1}$ Curriculum and Instruction Department, College of Education, King Saud University, Riyadh, Saudi Arabia \\ Correspondence: Curriculum and Instruction Department, College of Education, King Saud University, Riyadh, \\ Saudi Arabia.
}

Received: February 24, 2019 Accepted: April 4, 2019 Online Published: April 7, 2019

doi: 10.5539/elt.v12n5p55 URL: https://doi.org/10.5539/elt.v12n5p55

\begin{abstract}
This study examines the vocabulary knowledge of 120 Saudi tertiary students in order to scrutinise their ability to communicate in English. A vocabulary test constructed by Nation and Beglar (2007) was utilised in the study. The findings revealed that the mean vocabulary size of Saudi EFL tertiary students was roughly 3000 words. Nevertheless, most of the participants achieved low scores in the vocabulary low frequency levels. Some participants were unable to answer any item correctly in these low and mid frequency levels. This suggests that while those students might be able to communicate at a basic level, dealing with reading simplified texts and comprehending listening materials, they may struggle with reading authentic texts, producing a high quality of writing and watching English TV programmes and films.
\end{abstract}

Keywords: vocabulary, size, tertiary, knowledge, test

\section{Introduction}

Learning a new language simply cannot be done without absorbing vocabulary. 'Vocabulary learning is not a goal in itself; it is done to help learners listen, speak, read or write more effectively (Nation, 2001). This suggests that vocabulary is an essential element in developing language skills as will be discussed in section 3 . As discussed by Schmitt (2010), there have been numerous empirical studies into the importance of vocabulary. Schmitt (2010) describes the process of learning vocabulary as being done little by little, whilst Zhan-Xiang (2004) compares it to constructing a tall building brick by brick. All of this indicates that the process of learning vocabulary is ongoing, even for those at an advanced level.

Vocabulary is the foundation of an individual's capacity for language, both as a provider (when speaking and writing) and a recipient (when reading and listening). Therefore, it can be concluded that communication is not possible without vocabulary. Alderson (2005) compared individuals' results in a vocabulary test with other language skills tests, identifying a strong correlation between vocabulary and language skills. Consequently, Alderson (2005) asserted that the scope of a person's vocabulary has immense bearing on their language skills. This conclusion is in accordance with Thornbury (2002), who suggested that in order to possess effective communication skills, the learner must prioritise vocabulary over grammar.

Vocabulary learning is essential to developing the ability to communicate successfully. Indeed, according to Barani et al. (2010), communication is problematic without vocabulary. Learners who possess inadequate vocabulary pools typically struggle to properly express themselves, which can hinder them from imparting their true message. To describe this concept, Simon and Taverniers (2011) used the example of the fluency and flow of a conversation being impeded by the learner pausing to find a word. Zhan-Xiang (2004) noted that learners with a small vocabulary may find it problematic to express and expand upon their opinions in writing. Relatedly, when the majority of words they hear or read are unfamiliar to a learner, it is highly probable that they will not understand. Numerous studies, including those by Golkar and Yamini (2007), Zhang and Annual (2008), Al-Homoud and Schmitt (2009), and Brown (2010) found an interrelationship between vocabulary and reading, meaning that learners are more likely to understand a text when they recognise the words. Schmitt, Jiang and Grabe (2011) observed that several researchers propose that to understand a text, the learner should be familiar with $95 \%$ Laufer (1989) to $98 \%$ of the words (Hu \& Nation, 2010). Therefore, Harmer (2007) contended that in a classroom setting, reading texts is an effective means of providing students with new language contributions.

Teachers have become focused on vocabulary due to its significance in learning a new language being acknowledged. According to Nation (2001), the following 'four strands' should be part of an effective teaching 
course:

1) Meaning-focused input-utilising listening and reading activities to learn vocabulary

2) Language-focused learning-purposefully teaching and learning vocabulary

3) Meaning-focused output-employing speaking and writing activities to reinforce words that have previously been encountered

4) Fluency development-activities aimed at increasing learners' fluency in terms of their existing vocabulary pool

Simon and Taverniers (2011) conducted research that compared students' perspectives on the learning and teaching of English with regards to grammar, pronunciation, and vocabulary. This entailed a questionnaire being completed by more than 100 first-year English major students at a Belgian university. They found that in terms of communication, students placed greater importance on vocabulary than grammar or pronunciation. Furthermore, the students considered that vocabulary errors are more detrimental to effective communication than grammar or pronunciation mistakes. Zheng (2012) drew similar conclusions, having surveyed both teachers and students and determining that vocabulary is an essential component of learning English.

\section{Vocabulary Testing}

Vocabulary testing appears to be one of the crucial factors in teaching EFL learners since it shows the estimation of the vocabulary knowledge of learners. Vocabulary size is 'typically defined as the number of words in a language for which an individual has at least a basic form-meaning mapping knowledge' (Gyllstad, Vilkaite, \& Schmitt, 2015). That is, 'in order to teach vocabulary more effectively and better understand its relation to comprehension, we need first to address how vocabulary knowledge and growth are assessed' (Pearson, Hiebert, \& Kamil, 2007). Vocabulary testing can anticipate the ability to use a language (Nation \& Webb, 2011). Nation and Beglar (2007) highlighted the reasons behind the importance of vocabulary testing. First, it can provide information about learners' vocabulary size to know their ability to deal with different tasks, such as tasks related to reading and listening. Second, vocabulary testing is helpful in assessing the vocabulary development of learners. Third, it can be used to compare native speakers' vocabulary size with that of non-native speakers. Vocabulary tests can show 'the lexical gap' of learners in dealing with language skills (Read, 2007). Therefore, some vocabulary knowledge seems to be helpful, for both teachers and learners, as it determines the type of vocabulary to be taught and learned. There are two types of vocabulary knowledge: passive vocabulary knowledge which consists 'of lexical units that learners are able to recognise and understand, whereas active vocabulary comprises the repertoire of lexis they can use in speech or writing' (Doczi \& Kormos, 2016). Another distinction in vocabulary knowledge is related to depth and breadth, with depth based on the vocabulary size of the learner, and breadth concerning the quality of knowing vocabulary (Schmitt, 2010). Nation (2001) highlighted the importance of awareness in distinguishing between depth and breadth in vocabulary knowledge.

Three approaches can be adopted to test vocabulary knowledge including 'counting the words that someone produces', 'counting the number of words in a dictionary' and 'sampling from various frequency levels and testing to estimate the amount of vocabulary known at each level' (Nation \& Webb, 2011). There are a number of vocabulary tests that have been adopted by several studies (e.g. Al-Nujaidi, 2003; Al-Masrai \& Milton, 2012; Alqarni, 2019). Examples include the Vocabulary Levels Test (e.g. N. Schmitt, D. Schmitt, \& Clapham, 2001), the Vocabulary Size Test (Nation \& Beglar, 2007) and the CATSS (Computer Adaptive Test of Size and Strength) (Laufer \& Goldstein, 2004). These tests are in a multiple-choice format and have some advantages, as suggested by Gyllstad, Vilkaite and Schmitt (2015). These advantages include being easy to mark, the fact that learners are familiar with their format, and that a wide amount of vocabulary can be assessed. However, Wesche and Paribakht (1996) also reported a number of disadvantages. For example, guessing a correct answer plays a key role in these tests and the knowledge of the distractors may lead to the correct answer, rather than knowing the exact meaning of the target word. Also, these tests may overestimate the scores of the test takers as well as give rise to concerns regarding sampling rates while designing these tests (Gyllstad, Vilkaite, \& Schmitt, 2015). Although these tests are helpful in understanding and estimating learners' vocabulary knowledge, they only provide partial insights into learners' lexical knowledge (Meara, 2009). Ishii and Schmitt (2009) developed a vocabulary test to assess both the size and depth of vocabulary knowledge as well as being a suggested way for scoring this type of test. The researchers thought it was impossible to consider all aspects of word knowledge suggested by Nation (2001) in the proposed test; however, focusing on certain aspects was believed to be helpful. They concluded that vocabulary depth should be a crucial element in vocabulary tests, along with vocabulary size. 
Another type of vocabulary test format is the yes/no test. Although this type of test seems to be effective at providing a good estimation of vocabulary size, the scoring procedure remains questionable (Pellicer-Sánchez \& Schmitt, 2012). Pellicer-Sánchez and Schmitt (2012) conducted a study to examine the most effective approach for scoring yes/no tests. They compared two approaches: for the first, they looked at the time of participants' response to questions (timed yes/no test) to indicate whether the participants were accurate or inaccurate in answering the test (reaction time). In the second, the use of nonwords in the test was considered. No advantage was found for any of these approaches and they referred to other factors that could affect the effectiveness of the scoring. This finding supports Mochida and Harrington's (2006) finding in which no difference was found between the scores of the participants in the vocabulary knowledge test using a multiple choice format and a yes/no test. Schmitt (2010) argued that the most effective way to examine vocabulary knowledge is 'through interactive face-to-face interviews where the interviewer can probe the examinees [sic] lexical knowledge in detail and come to a very confident determination of this knowledge'. Although this way of testing appears to be helpful in providing a good indication of learners' vocabulary knowledge, it is also time-consuming, with only a few participants able to take the test when the test is used for research purposes.

The scores achieved by the testees indicate the vocabulary frequency level they have. Schmitt and Schmitt (2012) called for a reassessment of the vocabulary frequency level and whether the most frequent 2000 words are still sufficient to use English properly on the daily communication. Based on a review of a number of studies concerning vocabulary research, Schmitt and Schmitt (2012) argued that the most frequent 3000 words should be considered high frequency words, while 8000-9000 words should be included as low frequency words. Low frequency vocabulary includes words that are used infrequently, while high frequency vocabulary represents a large amount of the language (Nation, 2001). Schmitt and Schmitt (2012:495) suggested the following label to show the level of vocabulary frequency:

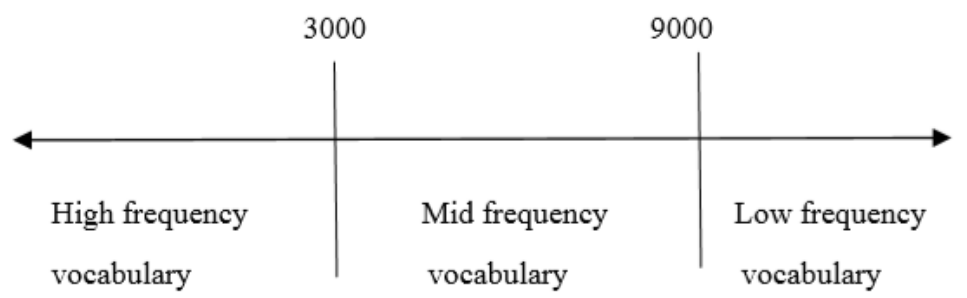

They also provided examples for the type of words used at each level:

3,001-4,000: academic, consist, exploit, rapid, vocabulary

4,001-5,000: agricultural, contemporary, dense, insight, particle

5,001-6,000: cumulative, default, penguin, rigorous, schoolchildren

6,001-7,000: axis, comprehension, peripheral, sinister, taper

7,001-8,000: authentic, conversely, latitude, mediation, undergraduate,

8,001-9,000: anthropology, fruitful, hypothesis, semester, virulent (N. Schmitt \& D. Schmitt, 2012).

This supports Cobb's (2007) argument that 'The first three of Nation's BNC lists (i.e. the 3000 most frequent word families) represent the current best estimate of the basic learner lexicon of English'. However, empirical research is needed to support such an argument.

In the classroom context, Horst (2010) examined an ESL advanced classroom discourse by analysing 121,000 word corpus of teacher speech. Only $2 \%$ of the words used by the teacher were at the mid frequency level, while 97\% were at the high frequency level. The researcher concluded that attending such classes seems to be unhelpful in acquiring much crucial vocabulary.

Other researchers examined vocabulary frequency in the textbook. For example, Matsuoka and Hirsh (2010) analysed vocabulary frequency in the upper intermediate New Headway English textbook to explore potential vocabulary learning opportunities. They found most of the vocabulary employed in the textbook was high frequency vocabulary, which suggests limited vocabulary learning opportunities. This is similar to the findings of recent research by Nordlund (2016). The researcher analysed two English text-books used in Sweden and showed that most of the vocabulary could be considered high frequency words. However, the results suggest that 
some of these words, mainly nouns, were unhelpful for learners at this stage.

\section{Relationship Between Vocabulary Size and Language}

Robust research has investigated the relationship between vocabulary size and language skills. For example, Stæhr (2008) explored the relationship between vocabulary knowledge and reading, listening and writing for 88 low level EFL learners. The study revealed a significant relationship between vocabulary size and reading and writing skills and to less extent listening skills. Although the study produced interesting findings, the test used in deciding the participants' proficiency in English skills seems not to be sensitive enough as it was based on a national test rather a standard English test. Similar results were found in Mehrpour and Rahimi's (2010) study, which showed vocabulary knowledge played a positive role in reading comprehension while there was no effect on listening comprehension.

In order to scrutinise the relationship between the vocabulary size and listening, Bonk (2000) carried out a study to examine this area by asking 59 Japanese EFL learners to listen to four short passages. A dictation test and written free recall test were used as research instruments. It was found that learners with $95 \%$ lexical coverage achieved better listening comprehension. This suggests that learners need high vocabulary knowledge to comprehend listening materials. Stæhr (2009) carried out a similar study that explored this area in more depth. 115 Danish EFL learners took part in the study, which suggest that learners need 98\% lexical coverage for listening comprehension. Van Zeeland and Schmitt (2013) found that the way of assessing lexical coverage in Stæhr's (2009) study was unhelpful. A more innovative research method was adopted in a similar study by van Zeeland and Schmitt (2013). Native $(\mathrm{N}=36)$ and non-native $(\mathrm{N}=40)$ speakers were involved in the research. The native speakers were employed to determine the difficulty of the listening comprehension of the listening recordings, which were based on short stories. Non-sense words were used in the recordings to ensure that each recording had certain lexical coverage. The results showed that learners need to know 2000-3000 word families in order to obtain listening comprehension.

Likewise, watching TV programmes or films requires a wide vocabulary size. Webb and Rodgers (2009) analysed $88 \mathrm{TV}$ programmes of different genres and revealed that the vocabulary knowledge needed to obtain $95 \%$ coverage was $2000-4000$ and $5000-9000$ to $98 \%$ coverage. Similar findings were revealed in the analysis of 318 films by Webb and Rodgers (2009), where the vocabulary size of 3000-4000 was seen as important to $95 \%$ coverage while 5000-10000 to $98 \%$ coverage. Although these studies showed that a reasonable vocabulary size (about 3000) could lead to comprehending the content of TV programmes and films, quite a high vocabulary size appeared necessary (about 9000) to reach a high level of comprehension.

High correlation was found between vocabulary knowledge and writing skill in a number of studies (e.g. Yu, 2010; Crossley \& McNamara, 2011; Olinghouse \& Wilson, 2013). A correlation was found between employing low frequency vocabulary and high writing scores (Crossley \& McNamara, 2011). Olinghouse and Wilson (2013) explored a different aspect of this area by examining the relationship between vocabulary knowledge and writing in relation to three different genres (story, persuasive, and informative writing). The results showed that the writing genre influenced the type of vocabulary used by the students. This suggests that having a low frequency vocabulary appears to be helpful in achieving a high competence in writing, since the level of vocabulary used in writing could affect the quality of writing.

Pertaining to the relationship between reading and vocabulary size, which was found a strong relationship, one of the earlier studies considering this aspect was conducted by Laufer (1989). She found $95 \%$ lexical coverage was necessary to obtain successful reading comprehension. Hu and Nation (2000) suggested a similar percentage (98\%) of lexical coverage was needed for reading comprehension of a fiction text. A more recent study by Schmitt et al. (2011) investigated this issue by employing 661 participants from 8 countries. A vocabulary test on the words used in the reading texts was adopted as well as a reading comprehension test. The researchers concluded that $98 \%$ lexical coverage was an appropriate percentage for reaching reading comprehension. To conclude, based on the studies discussed in this section, 95\%-98\% lexical coverage is key in order to comprehend both reading and listening materials, while a high frequency level of vocabulary is needed to produce a high quality of writing.

\section{Studies of Vocabulary Knowledge}

A number of vocabulary studies have been conducted to examine the vocabulary knowledge of EFL/ESL learners. One of these studies was by Mokhtar et al. (2010) who investigated the vocabulary size of university level Malaysian ESL 360 learners by comparing the participants' receptive and productive vocabulary knowledge. They recruited two tests to examine each aspect. The results suggested that the vocabulary size of those learners was limited. A longitudinal study by Webb and Ching-Shyang Chang (2012) investigated the 
vocabulary size of 166 university Taiwanese EFL learners over five years. The vocabulary size of nearly half of those learners in the last year at the university was 1000 words and only $16 \%$ of the learners' vocabulary size was 2000 words. Testing vocabulary knowledge is not solely done on EFL/ESL learners however, vocabulary knowledge of native English speakers can be examined as well. Interestingly, Coxhead, Nation and Sim (2015) tested the vocabulary size of 243 New Zealand secondary school students. The vocabulary test utilised examined the 20,000 vocabulary frequency level. The results showed that the participants had a large vocabulary size, with some of the participants knowing words at the 15000-17000 frequency level. These results support Biemiller and Slonim's (2001) results, which indicated the vocabulary size of Canadian native speakers of English aged six years old as 5200 words, rising to 8400 words at the age of nine. The results suggest that the vocabulary level increased over the years, with approximately two to three new words learned every day. It should be noted that the methodology adopted in this study was distinctive and in agreement with Schmitt's (2010) suggestions, with interviews used to examine the participants' vocabulary size rather the vocabulary test that is more commonly used by studies in this area.

In the Saudi context, there are only very few studies that have considered the vocabulary size of Saudi EFL leaners. Al-Nujaidi (2003) examined the vocabulary knowledge of Saudi first year university students using 2000-3000 vocabulary tests. The vocabulary knowledge for the students was found to be 500-700 words. This size of vocabulary does not enable learners to use English as the studies discussed in the previous section have shown. It should be noted that the participants in Al-Nujaidi's (2003) study had not studied English at primary school as English was only adopted in Saudi primary schools in 2004, as indicated earlier. The results of this study suggest that the participants were learning only approximately 100 words a year during their intermediate and secondary schooling. Another study by Al-Masrai and Milton (2012) explored the vocabulary knowledge of 92 Saudi university students, both at the beginning of their university studies and at the end. The findings revealed the vocabulary size of the students were 2000-3000 words on entry to the university and about 5000 at the end of the programme. It should be noted that the tests used in this study were different from the test used in Al-Nujaidi's (2003) study. This may suggest the potential reason for having different results in terms of students' vocabulary size at the start of their studies. A recent study by Alqarni (2019) compared the vocabulary size of 71 Saudi male and female university students at the end of their studies, and focused on certain vocabulary levels ( 2000 word level - 3000 word level - 5000 word level - 10000 word level) as well as an academic word list. Male students were outperformed by females and statistical differences were found. Another noteworthy finding from the study was that the students' vocabulary size was limited to the low frequency levels although they achieved high scores at the high frequency levels.

Most of the EFL/ESL studies discussed above show limited vocabulary size of learners, something which made teaching vocabulary in the contexts involved in these studies questionable and in need of improvement. The findings of the studies discussed in the previous section indicate that high vocabulary size is needed to reach a high level of comprehension and deal with reading, listening and watching TV.

\section{Statement of the Problem}

A number of researchers (e.g. Al-Akloby, 2001) have referred to the challenges in teaching and learning vocabulary in a Saudi context. Saudi students who complete secondary school seem to have a poor level of English, despite having spent on average six years studying it, with a limited English vocabulary (500-700 words) (Al-Nujaidi, 2003). Al-Seghayer (2017) referred to potential reasons for this, for example, new vocabulary is introduced in the classroom via a decontextualized method (e.g. word lists, flash cards) which may not contribute to students' communicative ability. Adopting the aforementioned vocabulary teaching techniques where certain aspects of vocabulary knowledge is neglected (e.g. synonym and antonym, homonymy etc.) negatively affect Saudi EFL learners' vocabulary knowledge (Abdalla, 2015). Also, there is limited use of vocabulary learning strategies in the classroom, including deploying dictionaries (Al-Bousaif, 2011). Since little is known about the vocabulary knowledge of Saudi tertiary students who have studied English for nine years, according to the new English textbook applied in 2004, the current study aims to investigate the following questions:

1). What is Saudi tertiary students' vocabulary size?

2). Do Saudi tertiary students have enough vocabulary to communicate in English?

\section{Method}

In total, 120 male Saudi tertiary students who had just enrolled at King Saud University participated in the current study. The participants' first language is Arabic and they belonged to roughly the same age category (18-19 years old). They started learning English at the age of 9, by studying English as a subject for three years at primary school with two (45 minutes) classes a week, while in intermediate and secondary school they 
attended four (45 minutes) classes a week. The participants answered a vocabulary test constructed by Nation and Beglar (2007). This tests receptive vocabulary knowledge and was designed to 'provide a reliable, accurate, and comprehensive measure of a learner's vocabulary size from the 1st 1000 to the 14 th 1000 word families of English' (Nation \& Beglar, 2007:9). Therefore, it is deemed 'an appropriate instrument for separating students with a wide range of proficiencies' (McLean \& Kramer, 2015). The participants took approximately 60 minutes to answer the test. The test consisted of 140 items, each item including four options for choosing the correct meaning of the target word. It should be noted that the last option in each item was "I do not know". The participants were required to select the correct definition of each word as shown in Appendix A.

\subsection{Data Analysis}

The scoring that followed was 1 point for a correct answer and 0 a wrong one. The total score of each participant was multiplied by 100 in order to reach the total vocabulary size as suggested by Nation and Beglar (2007). The mean and the standard deviation were used in the analysis.

\section{Results and Discussion}

In order to reveal the vocabulary size of the participants based on the vocabulary test used, descriptive statistics were calculated. Descriptive statistics of each vocabulary frequency level in the test was reported in Table 1. In Table 1, the results that show the mean, with the standard deviation of vocabulary size for Saudi EFL tertiary students, are summarised.

The results reveal that the mean for the total vocabulary size of the participants was roughly 3000 words. The highest vocabulary achieved was at the first 1000 level (mean 6.33, No. of words 760) while the lowest was at the thirteenth and fourteenth 13000-14000 levels (mean 0.73, No. of words 87). A considerable amount of the vocabulary was already known to participants on the second, third, fourth 2000, 3000, 4000 levels (mean 3.94, No. of words 473), (mean 3.53, No. of words 424), (mean 3.23, No. of words 387) respectively. Although some students were able to answer all items correctly at the first four levels, there were other students were unable to answer any item. This refers to significant individual differences between the participants. According to the finding on the average vocabulary size of the participants, this suggests a considerable number of the participants were possibly able to have a basic communication in English and could deal with reading simplified texts. Also, they would be able to have some level of listening comprehension since knowing 2000-3000 word families has been found to be helpful for listening comprehension (van Zeeland \& Schmitt, 2013). The vocabulary size of most of the participants would help them reach the nearly 95\% coverage needed for watching English TV programmes and films, based on Webb and Rodger's (2009) findings. However, the participants would not be able to reach high levels of comprehension for TV programmes and films since their vocabulary knowledge needed to be approximately 9000 words (Webb \& Rodgers, 2009). The vocabulary size for the majority of the participants appeared to be inadequate in dealing with authentic texts in English (e.g. newspapers, novels, etc.). Thus, the participants may find it challenging to write a high-quality composition where low frequency vocabulary is needed (Crossley \& McNamara, 2011; Olinghouse \& Wilson, 2013).

Table 1. Descriptive statistics of participants' performance in all test levels

\begin{tabular}{llll}
\hline Level & Mean & Std. Deviation & Sum \\
\hline 1000 & 6.33 & 2.132 & 760 \\
2000 & 3.94 & 2.623 & 473 \\
3000 & 3.53 & 2.146 & 424 \\
4000 & 3.23 & 2.371 & 387 \\
5000 & 1.90 & 2.251 & 228 \\
6000 & 1.78 & 1.746 & 213 \\
7000 & 1.62 & 2.087 & 194 \\
8000 & 1.60 & 1.964 & 192 \\
9000 & 1.38 & 1.524 & 166 \\
10000 & 1.26 & 1.678 & 151 \\
11000 & 1.27 & 1.586 & 152 \\
\hline
\end{tabular}




\begin{tabular}{llll}
\hline 12000 & 1.15 & 1.565 & 138 \\
13000 & 0.73 & 1.122 & 87 \\
140000 & 0.73 & 0.961 & 87 \\
Total & 30.43 & 18.912 & 3652 \\
T*TOTAL & 3043.33 & 1891.233 & 365200 \\
\hline
\end{tabular}

When these findings were compared with the studies conducted on native speakers (Coxhead, Nation, \& Sim 2015; Biemiller \& Slonim, 2001), dissimilar results were found. This was anticipated as the target sample in those studies were native speakers where English was their L1 while the participants in the current study were EFL. In comparison with the findings of other studies on the vocabulary size of EFL learners, the results of the present study contradict the results of several studies (e.g. Mokhtar et al., 2010; Webb \& Ching-Shyang Chang, 2012). The participants achieved higher vocabulary size than the participants achieved in the aforementioned studies. This may be due to the different vocabulary tests employed as well as the different backgrounds of the participants in those studies, in terms of them starting to learn English and the time allocated to English classes. The findings are incoherent with Al-Nujaidi's (2003) results using a similar sample. It should be noted that the participants in Al-Nujaidi's (2003) study did not learn English at primary school since learning English in Saudi primary only started in 2004. Also, a different vocabulary test was recruited. This might mean a difference in vocabulary size for the participants although they were similar to the participants in the present study, which they were Saudi tertiary EFL Students. Another potential for such difference may be due to the increasingly widespread use of technology containing English content, leading to high exposure to English.

The estimation of participants' vocabulary size in the present study fits well with estimates of vocabulary size found in Al-Masrai and Milton's (2012) study; this suggested vocabulary size of Saudi EFL students was 2000 3000 words on entry to university. Despite a different vocabulary test used in Al-Masrai and Milton's (2012) study, the findings were similar. It should be mentioned that both studies recruited a similar sample of participants although the number of participants in the current study was larger.

Insightful findings can be revealed when the results of the current study are compared to Alqarni's (2019) study. Similar participants were recruited in both studies. While the students in Alqarni's (2019) study were in their final semester at university, the students in this study had just joined the same university. Table 2 summarises the difference between the students' vocabulary size in Alqarni's (2019) study and those in the current study.

Table 2. Comparison between the students' vocabulary size in Alqarni's (2019) study and those in the current study

\begin{tabular}{llll}
\hline Vocabulary frequency level & Alqarni (2019) & Current study & Difference \\
\hline 2000 & 876 & 473 & 403 \\
3000 & 725 & 424 & 301 \\
5000 & 580 & 228 & 352 \\
10000 & 254 & 151 & 103 \\
\hline
\end{tabular}

These differences highlight the students' vocabulary development over the four university years by estimating the vocabulary learned at each vocabulary level. These figures might suggest that the students' vocabulary development at the College of Languages and Translation over these years was quite limited. This finding corroborates Alqarni's (2019) conclusion on the need for more attention and consideration to be paid to vocabulary learning at university. The comparison shown in Table 2 may also suggest that the students learned a considerable number of high frequency words over the four years at university and yet a limited number of low frequency words were learned. It should be noted that the students in Alqarni's (2019) study specialised in translation studies, where a large vocabulary knowledge was required including low frequency words.

\section{Conclusion}

The results of this study have revealed the vocabulary size of Saudi EFL tertiary students, with the mean vocabulary size standing at approximately 3000 words. The study showed low achievements of participants at the low frequency vocabulary level. At certain levels, some of the participants were unable to provide any correct 
answer. These findings provide an insight into the level of those students in the use of English and to what extent they are able to cope with different skills. Based on the findings of this study, the students can manage basic communication in English with the ability to read simplified texts as well as comprehend listening materials. Nevertheless, reading authentic texts, watching English TV programmes and films and writing high quality compositions would be challenging tasks for them. Therefore, more attention should be given to vocabulary learning in schools and universities. Although the current study provided an insight into the vocabulary size of Saudi EFL tertiary students, which reflected their potential ability to communicate in English, one of the limitations should be considered in the future research. Some of the students might have studied English at private or international schools where high attention is given to English. This variable may influence the general findings in such research.

\section{References}

Abdalla, A. (2015). Promoting lexical knowledge in the Saudi tertiary EFL classroom at Taif University. International Journal of Social Sciences and Humanities Research, 3(3), 86-92.

Al-Akloby, S. (2001). Teaching and learning English vocabulary in Saudi Arabian public schools: An exploratory study of some possible reasons behind failure to learn English vocabulary. (Unpublished Doctoral Thesis, University of Essex, Colchester).

Al-Bousaif, M. (2011). Factors determining Saudi learners' difficulties in attaining EFL vocabulary. (Unpublished Doctoral Thesis, University of Newcastle, Newcastle).

Alderson, J. C. (2005). Diagnosing foreign language proficiency: The interface between learning and assessment. Continuum: London.

Al-Homoud, F., \& Schmitt, N. (2009). Extensive reading in a challenging environment: A comparison of extensive and intensive reading approaches in Saudi Arabia. Language Teaching Research, 13(4), 383-401. https://doi.org/10.1177/1362168809341508

Alqarni, I. R. (2019). Receptive vocabulary size of male and female Saudi English major graduates. International Journal of English Linguistics, 9(1), 111-119. https://doi.org/10.5539/ijel.v9n1p111

Al-Nujaidi, A. (2003). The relationship between vocabulary size, reading strategies, and reading comprehension of EFL learners in Saudi Arabia. (Unpublished Doctoral Thesis, Oklahoma State University, Stillwater).

Al-Seghayer, K. (2017). Reality and challenges of TEFL in 21st-century Saudi Arabia. Riyadh: Hala Print Co.

Barani, G., Mazandarani, O., \& Rezaie, S. H. H. (2010). The effect of application of picture into picture audiovisual aids on vocabulary learning of young Iranian ELF learners. Procedia Social and Behavioral Sciences, 2(2), 5362-5369. https://doi.org/10.1016/j.sbspro.2010.03.874

Biemiller, A., \& Slonim, N. (2001). Estimating root word vocabulary growth in normative and advantaged populations: Evidence for a common sequence of vocabulary acquisition. Journal of Educational Psychology, 93(3), 498-520. https://doi.org/10.1037/0022-0663.93.3.498

Bonk, W. J. (2000). Second language lexical knowledge and listening comprehension. International Journal of Listening, 14(1), 14-31. https://doi.org/10.1080/10904018.2000.10499033

Brown, F. A. (2010). Vocabulary knowledge and comprehension in second language text processing: A reciprocal relationship? Asian EFL Journal, 12(1), 88-133.

Cobb, T. (2007). Computing the vocabulary demands of L2 reading. Language Learning \& Technology, 11(3), 38-63.

Coxhead, A, Nation, I. S. P., \& Sim, D. (2014). Creating and trialling six forms of the Vocabulary Size Test. TESOLANZ Journal, 22, 13-26.

Coxhead, A., Nation, P., \& Sim, D. (2015). Measuring the vocabulary size of native speakers of English in New Zealand secondary schools. New Zealand Journal of Educational Studies, 50(1), 121-135. https://doi.org/10.1007/s40841-015-0002-3

Crossley, S. A., \& McNamara, D. S. (2011). Understanding expert ratings of essay quality: Coh-Metrix analyses of first and second language writing. International Journal of Continuing Engineering Education and Life Long Learning, 21(2-3), 170-191. https://doi.org/10.1504/IJCEELL.2011.040197

Dóczi, B., \& Kormos, J. (2016). Longitudinal developments in vocabulary knowledge and lexical organization. New York: Oxford University Press. https://doi.org/10.1093/acprof:oso/9780190210274.001.0001 
Golkar, M., \& Yamini, M. (2007). Vocabulary, proficiency and reading comprehension. The Reading Matrix, 7(3), $88-112$.

Gyllstad, H., Vilkaite, L., \& Schmitt, N. (2015). Assessing vocabulary size through multiple-choice formats: Issues with guessing and sampling rates. International Journal of Applied Linguistics, 166(2), 276-303.

Harmer, J. (2007). The practice of English language teaching (4th ed.). Pearson Education Limited: Harlow. https://doi.org/10.1093/elt/ccn029

Horst, M. (2010). How well does teacher talk support incidental vocabulary acquisition? Reading in a Foreign Language, 22(1), 161-180.

Hu, M. \& Nation, P. (2000). Unknown vocabulary density and reading comprehension. Reading in a Foreign Language, 13(1), 403-430.

Ishii, T., \& Schmitt, N. (2009). Developing an integrated diagnostic test of vocabulary size and depth. RELC, 40(1), 5-22. https://doi.org/10.1177/0033688208101452

Laufer, B., \& Goldstein, Z. (2004). Testing vocabulary knowledge: Size, strength, and computer adaptiveness. Language Learning, 54(3), 399-436. https://doi.org/10.1111/j.0023-8333.2004.00260.x

Laufer, B. (1989). What percentage of text-lexis is essential for comprehension? In C. Lauren, \& M. Nordmann (Eds.), Special language: From humans thinking to thinking machines (pp. 316-323). Clevedon: Multilingual Matters.

Masrai, A., \& Milton, J. (2012). The vocabulary knowledge of university students in Saudi Arabia. TESOL Arabia Perspectives, 19(3), 13-20.

Matsuoka, W., \& Hirsh, D. (2010). Vocabulary learning through reading: Does an ELT course book provide good opportunities? Reading in a Foreign Language, 22(1), 56-70.

Mehrpour, S., \& Rahimi, M. (2010). The impact of general and specific vocabulary knowledge on reading and listening comprehension: A case of Iranian EFL learners. System, 38(2), 292-300. https://doi.org/10.1016/j. system.2010.01.004

Meara, P. M. (2009). Connected words: Word associations and second language vocabulary acquisition. Amsterdam: Benjamins. https://doi.org/10.1075/11lt.24

McLean, S., \& Kramer, B. (2015). The creation of a new vocabulary levels test. Shiken, 19(2), 1-11.

Mochida, K., \& Harrington, M. (2006). The Yes/No test as a measure of receptive vocabulary knowledge. Language Testing, 23(1), 73-98. https://doi.org/10.1191/02655322061t321oa

Mokhtar, A. A., Rawian, R. M., Yahaya, M. F., Abdullah, A., Mansor, M., Osman, M. I., ... Mohamed, A. R. (2010). Vocabulary knowledge of adult ESL learners. English Language Teaching, 3(1), 71-80. https://doi.org/10.5539/elt.v3n1p71

Nation, I. S. P. (2001). Learning vocabulary in another language. Cambridge: Cambridge University Press. https://doi.org/10.1017/CBO9781139524759

Nation, I. S. P. \& Webb, S. (2011). Researching and analyzing Vocabulary. Boston: Heinle Cengage Learning.

Nation, I.S.P. \& Beglar, D. (2007) A vocabulary size test. The Language Teacher, 31(7), 9-13.

Nordlund, M. (2016). EFL textbooks for young learners: A comparative analysis of vocabulary. Education Inquiry, 7(1), 47-68. https://doi.org/10.3402/edui.v7.27764

Olinghouse, N. G., \& Wilson, J. (2013). The relationship between vocabulary and writing quality in three genres. Reading and Writing, 26(1), 45-65. https://doi.org/10.1007/s11145-012-9392-5

Pearson, P., Hiebert, E., \& Kamil, M. (2007). Vocabulary assessment: What we know and what we need to learn. Reading Research Quarterly, 42(2), 282-296. https://doi.org/10.1598/RRQ.42.2.4

Pellicer-Sánchez, A. \& Schmitt, N. (2012). Scoring Yes-No vocabulary tests: Reaction time vs. nonword approaches. Language Testing, 29(4), 489-509. https://doi.org/10.1177/0265532212438053

Read, J. (2007). Second language vocabulary assessment: Current practices and new directions. International Journal of English Studies, 7(2), 105-125.

Schmitt, N. \& Schmitt, D. (2014). A reassessment of frequency and vocabulary size in L2 vocabulary teaching. Language Teaching, 47(4), 484-503. https://doi.org/10.1017/S0261444812000018 
Schmitt, N., Schmitt, D., \& Clapham, C. (2001). Developing and exploring the behaviour of two new versions of the Vocabulary Levels Test. Language Testing, 18(1), 55-88. https://doi.org/10.1177/026553220101800103

Schmitt, N., Jiang, X., \& Grabe, W. (2011). The percentage of words known in a text and reading comprehension. The Modern Language Journal, 95(1), 26-43. https://doi.org/10.1111/j.1540-4781.2011.01146.x

Schmitt, N. (2010). Researching vocabulary: A vocabulary research manual. Houndmills: Palgrave Macmillan. https://doi.org/10.1057/9780230293977

Simon, E., \& Taverniers, M. (2011). Advanced EFL learners' beliefs about language learning and teaching: A comparison between grammar, pronunciation, and vocabulary. English Studies, 92(8), 896-922. https://doi.org/10.1080/0013838X.2011.604578

Sun, Y. C. (2010). Extensive writing in foreign language classrooms: A blogging approach. Innovations in Education and Teaching International, 47(3), 327-339. https://doi.org/10.1080/14703297.2010.498184

Stæhr, L. S. (2008). Vocabulary size and the skills of listening, reading and writing. Language Learning Journal, 36(2), 139-52. https://doi.org/10.1080/09571730802389975

Stæhr, L. (2009). Vocabulary knowledge and advanced listening comprehension in English as a foreign language. Studies in Second Language Acquisition, 31(4), 577-607. https://doi.org/10.1017/S0272263109990039

Thornbury, S. (2002). How to teach vocabulary. London: Longman.

Van Zeeland, H., \& Schmitt, N. (2013). Incidental vocabulary acquisition through L2 listening: A dimensions approach. System, 41(3), 609-624. https://doi.org/10.1016/j.system.2013.07.012

Webb, S., \& Rodgers, M. P. (2009). Vocabulary demands of television programs. Language Learning, 59(2), 335-366. https://doi.org/10.1111/j.1467-9922.2009.00509.x

Webb, S. A., \& Chang, A. C. S. (2012). Second language vocabulary growth. RELC, 43(1), 113-126. https://doi.org/10.1177/0033688212439367

Wesche, M., \& Paribakht, T. S. (1996). Assessing second language vocabulary knowledge: Depth versus breadth. Canadian Modern Language Review, 53(1), 13-40. https://doi.org/10.3138/cmlr.53.1.13

Zhang, L. J., \& Anual, S. B. (2008). The role of vocabulary in reading comprehension: The case of secondary school students learning English in Singapore. RELC, 39(1), 51-76. https://doi.org/10.1177/0033688 208091140

Zhan-Xiang, M. (2004). The necessity of intensifying English vocabulary teaching in the remote minority area college English teaching. Asian EFL Journal, 6(2), 25-31.

Zheng, S. (2012). Studies and suggestions on English vocabulary teaching and learning. English Language Teaching, 5(5), 129-137. https://doi.org/10.5539/elt.v5n5p129

\section{Appendix A}

Vocabulary Size Test (Sample)

Circle the letter a-e with the closest meaning to the key word in the question.

1. SEE: They saw it.

a. cut

b. waited for

c. looked at

d. started

e. I do not know

2. TIME: They have a lot of time.

a. money

b. food

c. hours

d. friends 


\section{e. I do not know}

3. PERIOD: It was a difficult period.

a. question

b. time

c. thing to do

d. book

e. I do not know

* The full test is available at https://www.victoria.ac.nz/lals/about/staff/paul-nation\#vocab-tests

\section{Copyrights}

Copyright for this article is retained by the author(s), with first publication rights granted to the journal.

This is an open-access article distributed under the terms and conditions of the Creative Commons Attribution license (http://creativecommons.org/licenses/by/4.0/). 